\title{
The Analysis of Phrasal Verbs and Its Vicinity in Elizabeth Gilbert's Eat, Pray, Love
}

\author{
Octa Pratama Putra, S.S., M.Pd \\ Bina Sarana Informatika University \\ octa.opp@bsi.ac.id
}

Article History:

First Received:

$10 / 04 / 2021$

Final Revision:

$22 / 06 / 2021$

Available online:

$30 / 06 / 2021$

\begin{abstract}
The aim of this study earnestly regards to the forefront of phrasal verbs and its vicinity. After the writer reaps the phrasal verb, the writer contrives them into four sub-divisions: they are: intransitive, transitive, inseparable, and separable phrasal verb. The data are collected from Eat, Pray, Love novel by Elizabeth Gilbert. The result shows that, they are shown 20 phrasal verbs; they are 17 transitive phrasal verbs, 5 intransitive phrasal verbs, 3 separable phrasal verbs, and 10 inseparable phrasal verbs. The conclusion tells, within the novel, it has been classified all about the phrasal verbs the writer has been conducted yet. Concerning to the four classifications of phrasal verbs that the writer has scoped and found out, hereby it is stated that phrasal verb, definitely, has an exact definition. Certainly, it needs an understanding of current context first (read and understand in a certain dialogue or conversation inside that novel of Eat, Pray, Love) to know what the meaning of that case or topic being conveyed is.
\end{abstract}

Keywords: phrasal verb, separable \& inseparable phrasal verbs, transitive \& intransitive phrasal verbs, types of phrasal verb

\section{http://jos.unsoed.ac.id/index.php/ies}

\section{INTRODUCTION}

Professing in general, that, a language can be defined as a conspicuous tool for communication which has sounds and symbols that enables to convey the ideas, thoughts, and feelings to someone. According to Jamil and Nasrum in Hornby's perceptible statement, he said (Hornby, 2018) language is the system of communication in speech that is used by people of particular country and the way of expressing ideas and feeling using movement, symbol and sound." That preconceived-notion means that, language has an important role in communication process. The communication itself is a process where the communicator, or she or he that communicates something, delivers the message, which he or she has in mind. That matter is given to the communicant in order the message to be received correctly as the communicator's intention perceptibly and clearly. Upon this statement, a language is needed in this process. Then, the communicator must have a language skill.

The rapport between that previous paragraph and the following statement state that, the study of human language is called linguistics. (Nordquist, 2013) 
described, "Everyone will agree that linguistics is concerned with the lexical and grammatical categories of individual languages, with differences between one type of language and another, and with historical relations within families of languages." (Rahmawati, 2013) in Azar's statement, "A phrasal verb consists of a verb and a particle (or two particles) that in fixed combination have a single meaning."

Getting to broach a subject, a sentence must be espoused with subject and predicate (verb). If there is only a subject without a predicate, it is amiss, it cannot be said as a sentence. In English, there are two types of verb; they are transitive and intransitive. Transitive verb is a verb that needs an object, contrariwise; intransitive verb does not need an object. There is also a kind of verb in English, it is phrasal verb. This kind of verb usually has idiomatic meaning, because the meaning of the verb followed by a particle is different from the verb stands by itself. Therein, the verb can be classified as phrasal verb if it is followed by particle.

In this journal, categorically, the writer analyzes phrasal verb. It is an interesting standpoint to be analyzed because the meaning of the verb in phrasal verb will be different if the verb stands by itself. Phrasal verb is commonly used in conversation rather than in writing. Non-native English speakers find difficulty in reading text or in a communication using phrasal verbs. The same word followed by different particles lead to different meaning. The writer finds and analyzes the phrasal verbs based on a Eat, Pray, Love novel by Elizabeth Gilbert.

So then, the writer has an interesting thing in discussing the matter of what phrasal verb and its vicinity. It is stated, because phrasal verb is extremely common in everyday usage and is made with some of the most frequently used verbs and particles in English. Thence, as from the perspective of writer, reading fiction (novel) turns out a great way to develop the social brain. Reading novels, for simply saying, will be shaping the brains and molds the social skills, too.

\subsection{Definition of Phrasal Verb}

According to (Webster, 2021), a phrase (such as take-off or look down on) that combines a verb with a preposition or adverb or both and that functions as a verb whose meaning is different from the combined meanings of the individual words.

Alongside of that matter, for some of common verbs used in phrasal verbs are 'come', 'go', 'look', 'make', 'put', 'take' and so on. Then, some popular particles that form phrasal verbs are 'at', 'away', 'down', 'off', 'on', 'out', and many more. However, one of the meanings of 'put out' is 'to leave a port'. It is chiefly concluded that not only are phrasal verbs the basic structures of utterances, but also, they exist as complete meaningful units.

(Tu, 2019) in Stephen defines distinctly, a phrasal verb as a combination of a verb and one or two particles, all of which function as a single word. In addition, an adverb, a preposition or even both adverb and preposition can act as particles. Lock (Lock, 1996) described, "Some verb + preposition + noun group sequences can be analyzed as verbs followed by Circumstantial Adjunct. Others can be analyzed as phrasal verbs followed by a Goal or Range; that is, the prepositions are actually particles attached to the verbs." It can be concluded that phrasal verbs are a combination form of some verb + preposition + noun group sequences. The preposition, itself is a particle that follows the verbs. 
(Greenbaum, Sidney and Nelson, 2002) enunciate, "Phrasal verbs and prepositional verbs are combination of a verb and one particle, whereas phrasalprepositional verbs have two particles. A prepositional verb requires an object to complete the sentence." It means, phrasal verbs and prepositional verbs are constructed from a verb and one particle which come together, but phrasalprepositional verbs have two particles and it needs an object to complete the sentence.

As procuring from another statement of what phrasal verb is, it is taken from (Mutiara, Sofwan, 2017) in Courtney's statement, it tells that, idiomatic expression of phrasal verb is a combination of a verb and a preposition or adverb that creates a meaning different from its original.

From some experts' statements above, the writer has a drawn conclusion that phrasal verb is a combination of word and preposition or particle. The particle can be preposition (e.g., off, on) or adverb of direction (e.g., away, back). It is sometimes called as prepositional verbs. Phrasal verb has a complement. It comes after the adverbial particle or between the verb and the adverbial particle but it is also possible that phrasal verb without a complement.

\subsubsection{Definition of Transitive and Intransitive Phrasal verbs}

Phrasal verbs are a combination of a verb and one particle, e.g., 'give in' and 'blow up'. There are transitive and intransitive phrasal verbs. However, (Fiktorius, 2019) said, transitive phrasal verb requires an object but intransitive phrasal verb does not require an object.

\begin{tabular}{|c|c|c|c|}
\hline bring it back & call them up & cross it off & dig it up \\
\hline dream it up & eat it up & fill it up & give it away \\
\hline give it up & hand it in & hand it over & hold it down \\
\hline hold it up & knock it over & leave it out & lift it up \\
\hline mess it up & mix it up & pass it around & pin it up \\
\hline pay it back & put it away & read it out & switch it off \\
\hline switch it on & throw it away & throw it out & tidy it away \\
\hline tidy it up & try it on & try it out & turn it off \\
\hline turn it on & wash it out & wipe it off & wipe it out \\
\hline
\end{tabular}

Figure 2.1 - (Andria, 2021) The Example of Transitive Phrasal verbs 


\begin{tabular}{|c|c|c|c|}
\hline \multicolumn{4}{|c|}{ Following is a list of common intransitive phrasal verbs } \\
\hline come away & come back & come in & come out \\
\hline end up & fall apart & fall over & fool around \\
\hline get up & go ahead & go away & go back \\
\hline go on & go out & grow up & hold on \\
\hline join in & lie down & look back & meet up \\
\hline move over & own up & roll over & run around \\
\hline run away & run out & sit down & stand up \\
\hline walk out & watch out & & \\
\hline
\end{tabular}

Figure 2.2 - (Andria, 2021) The Example of Intransitive Phrasal verbs

\subsubsection{Definition of Prepositional Verbs}

The definition of prepositional verb is meant as a verb that is followed by a preposition. As (Yuliastuti, 2008) said, the prepositional verbs are multi-words verbs that consist of a verb followed by a prepositional particle. The particles can be prepositions or prepositional adverbs that functions a preposition. Simply stated of Prepositional Verb = Verb + Preposition. Example: 'She is waiting for him', 'We believe in God', and 'I listen to the music.'

\subsubsection{Phrasal-Prepositional Verbs}

Phrasal-prepositional verbs have two particles, e.g. 'look down on', 'catch up with', and 'put up with'. There are two types of phrasal-prepositional verbs, which have two particles (an adverb followed by a preposition).

According to the pattern of phrasal verb (Greenbaum, Sidney and Nelson, 2002) the writer concludes that multi-word verbs are combination of a verb and one or more other words. The most frequent types of multi-word verbs consist of a verb followed by one or more particles.

\subsubsection{Separable Phrasal Verbs}

Skidding to the next part, it is the separable phrasal verb. It means, it can separate the two words and put the direct object in the middle. (Anggraeni, 2020) A separable phrasal verb is a verb and particle that can be separated and objects can be placed in the middle between verbs and particle. Example: I really like this dress. Can I try it on? and Could you tell me your e-mail address again? I didn't write it down. 


\subsubsection{Inseparable Phrasal Verbs}

The impending context is called as the transitive phrasal verb. It does not allow an object to be placed between the verb and particle. (Monika, 2020) Some phrasal verbs cannot be separated. This means that, when using an object, it must always come after the complete phrasal verb. This is true when using a noun (Ellen, the car, our friends, Germany) or a pronoun (him, them, us.) The object must always come after the complete phrasal verb. The example: "What does e.g., stand for? It $\underline{\text { stands }}$ for Example Gratia" and "We need to check out of the room by 1:30!"

Overall, it is purposed to know, recognize, and understand about what phrasal verbs are and the parts or things related to it. They are frequently common in conversations, and that makes them essential to be either mastering or understanding the certain conversation or topic; as for this time, it is a novel.

\section{RESEARCH METHOD}

This paper uses the quantitative methods as the way of creating and completing it. For finishing it, the writer has read, underlined, and noted all the necessary things related to the phrasal verb. Afterwards, the writer classifies it each other. Here, the writer has to read, understand, get the idea for the entire context, comprehend the deep meaning, then categorize it eventually.

This kind of method -quantitative-, where it does not have any calculation or statistical matter of involving numbering and so on. It has been done of conducting it by providing a full or entire of text provided; where it shows only the pure and genuine analysis within the novel itself to be conveyed into this journal.

(Aryani, 2019) "This qualitative research served the data in the form of word, not in the form of number, graphic, statistic or other quantitative forms." As for other's perspective about what qualitative research as the method is, it is from (Wikasitakusumaning, 2018), who elaborates: "The analyses in qualitative research concern in understanding the result of found data rather than calculate the result of found data."

Then, it is simplified that, the qualitative research method tells to a type of research of certain or particular matter, that collects and works with non-numerical data and that seeks to interpret meaning from the obtained-data. So, qualitative research is the process of collecting, analyzing, and interpreting non-numerical data; as for this subject is such as language that refers to a novel.

\section{RESULT AND DISCUSSION}

These following paragraphs are discussing about what the writer has got and underlined of English phrasal verbs from the novel of Eat, Pray, Love by Elizabeth Gilbert. Based on typically of phrasal verbs, here is the discussion that the writer found; they are shown 20 phrasal verbs; they are 17 transitive phrasal verbs, 5 intransitive phrasal verbs, 3 separable phrasal verbs, and 10 inseparable phrasal verbs.

Then, as being taken from (Longman Dictionary of Contemporary English, 1978) The word of agree is a reciprocal verb. This type of verb is used when saying that two or more people or groups do something that involves both or all of them. For example: My wife and I agree on most things. It is understood that, those people are about having the same subject. It is syntactically from the novel, "If we can't agree on who sleeps where, we'll have to switch off." Explanation: It is perceptibly 
stated, the phrasal is agree on. It is asserted as the phrasal verb because there is a verb agree and a particle on. It is classified into transitive inseparable phrasal verb because, after the phrasal verb agree on, it is directly followed by direct object who sleeps where. It means 'to have agreement'. The character there shows deals or keeps along; having the same aim or purpose for that case within the story.

Next, according to (Collins English Dictionary, 1979) If someone bursts into tears, laughter, or song, it is meant he or she suddenly begins to cry, laugh, or sing. Also, if somebody says that something bursts into a particular situation or state, it means, it suddenly changes into that situation or state. In general, for example is: She burst into tears and ran from the kitchen. It is taken one utterance from the novel; "Alicia suddenly bursts into tears." Explanation: It is peering out that, the phrasal verb on that sentence is burst into. It is procured as phrasal verb because, there is a verb burst and a particle into. The crux tells that, transitive inseparable phrasal verb, because after the phrasal verb burst into, it is directly followed by direct object tears. So, it is defined as 'to begin to cry'. Literally, it is also stated to add the beauty of words in this literary work; it is not only just about to write the word of cry offhand. However, that comes up with two words; burst + into (tear).

Based on the (Macmillan Dictionary, 2002), to physically carry someone or something to many places; to tote someone or something around. A noun or pronoun can be used between "carry" and "around." Example: After carrying a toddler around all day, my arms are pretty sore. Now, as it is syntactically got from the novel: "Now she understood why Arthur carried around a very large whistle." Explanation: It is professed that, the phrasal verb on that sentence is carried around. It is called phrasal verb because there is a verb carried and a particle around. Then, it is classified into transitive inseparable phrasal verb because after the phrasal verb carried around, is directly followed by direct object a very large whistle. It means 'always bring'. That character shows the consistency of having or bringing that scene of that novel. It states as having to bring or take along that stuff frequently.

In accordance with (Kamus Inggris, 2000), when someone checks things off, perhaps, he or she checks or counts it while referring to a list of a particular matter; to make sure that he or she has considered all of those particular items. Example: Once you've checked off the items you ordered, put this record in your file, please. It is gotten from the novel; "Sabrina checked off her name just a snake crawled." Explanation: It is enunciated as the phrasal verb on that sentence is checked off. It is called phrasal verb because there is a verb checked and a particle off. It is classified into transitive inseparable phrasal verb because after the phrasal verb checked off, it is directly followed by direct object her name. It means, 'to mark or cross'. It assumes that, the character does a little thing. What it means, she does an action of giving a particular thing, it is said to be giving the sign of it.

It is known from (Webster, 2021) the word 'come' is from Germanic origin; meaning to arrive. It has been in use since before the 1800's. So, for the come over, it is to move closer to someone or something. Example: I had to go home from work today as a terrible about of nausea came over me, I think that it must have been something that I ate. It is being taken from the novel; "An intense look came over her face." Explanation: It is seen distinctly as the phrasal verb, came over. It is called phrasal verb because there is a verb came and a particle over. It is classified into 
transitive inseparable phrasal verb because after the phrasal verb came over, it is directly followed by direct object her face. It means 'to approach'. It is shortly said, that kind of a look appears to be coming near, while for this context, it points out the look which is seen intensely.

The current context, it is crawl in. Based on (Collins English Dictionary, 1979), it is to move on one's hands and knees. On the similar meaning, it is to move slowly in a prone position without or as if without the use of limbs. For example: The snake crawled into its hole. So, as being taken syntactically from the novel "...a gigantic snake crawled in through the window." Explanation: The cogent reason of declaring as phrasal verb because that sentence shows crawled in. It is called phrasal verb because there is a verb crawled and a particle in. It is classified into transitive inseparable phrasal verb because after the phrasal verb crawled in, it is not directly followed by direct object the window but there is the word through before the object. It means 'to enter creepily'. That person of novel conducts a move forward on the hands and knees or by dragging the body close to the ground or being stretched out along a surface. This context, the giant snake is exposed.

For having the reference of (Collins English Dictionary, 1979), the word dash out means someone is about to leave a place in a hurry to get something. For instance: Harry dashed out for some cigarettes. So, it is syntactically taken from the novel; "... and Salem dashed out the door, running right passed her." Explanation: Thence, it is expounded that, the phrasal verb on that sentence is dashed out. It is called phrasal verb because there is a verb dashed and a particle out. It is classified into transitive inseparable phrasal verb because after the phrasal verb dashed out, it is directly followed by direct object the door. It means 'to leave a place in hurry'. Then, it is implied in that novel, that guy runs or goes somewhere very quickly because in a hurry condition. It is also can be said in a glimpse by referring to hurry away or depart hastily.

The drop at can be defined as, from (Macmillan Dictionary, 2002), to move to another level, or cause something to move to a certain level. Example: Jessi saw what Toni saw, but she wasn't going to drop at Xander's feet. As being taken from the novel; "...through the window and dropped at her feet." Explanation: That phrasal verb through into the adjoining sentence is dropped at. It is called phrasal verb because there is a verb dropped and a particle at. It is classified into transitive inseparable phrasal verb because after the phrasal verb dropped at, it is directly followed by direct object her feet. It means 'to fall to.' It is presumably the character shown there tries to have stuff -or a similar thing like that- being dropped or being fallen at the feet of that person.

The word find out can be meant by (Macmillan Dictionary, 2002) to discover a fact or piece of information. Also, it is to learn something that she or he does not already know, especially by making a deliberate effort to do so. Sentence example: It makes you want to watch the next episode to find out what's going to happen. It is syntactically taken from the novel; "Oh well, I'll find out soon enough." Explanation: That statement rivets on phrasal verb which tells find out. It is called phrasal verb because there is a verb find followed by a particle out. The word find out on that sentence is included in intransitive phrasal verb because after the phrasal verb there is no direct object. It is classified into inseparable phrasal verb because between the word find and the particle out there is no object. It means 'to discover'. As being 
looked from that novel, the character there needs a moment to peer out that current case. In addition, it is to get the information about something because that character wants to know more about that; or it is to learn a fact or piece of information as well.

The word follow out, according to (Dictionary, 1999), can be referred to fulfill or accomplish something; to carry something out. For instance: Make sure the cat doesn't follow you out of the house. It is syntactically taken from the novel; "... to feel really heavy, and followed Mitch out the door." Explanation: Phrasal verb on that sentence is followed out. It is called phrasal verb because there is a verb followed and a particle out. It is classified into transitive-separable phrasal verb because there is an object between the verb followed and the particle out. It means 'to go out after someone'. Here, the person of being discussed there is meant to trail closely behind someone, he is Mitch, while exiting some place or thing away in that novel.

As being got form the (Collins English Dictionary, 1979), the word phrasal verb 'steer forward' means: To attempt to convince or persuade someone to choose, consider, or become involved with someone or something. In this usage, a noun or pronoun is used between "steer" and "toward." Example: The police officer told me to steer the car toward a checkpoint on the side of the road. It is syntactically taken from the novel; ".... And steered her toward the door." Explanation: Phrasal verb on that sentence is steered. It is called phrasal verb because there is a verb steered and a particle toward. It is classified into transitive-separable phrasal verb because there is an object between the verb steered and the particle toward. The object is a pronoun her. The pronoun her is direct object because it comes before the particle and a noun the door is a prepositional object because it follows the particle toward. It means 'to turn to something'. It is regarded to a guide (or aim). Then, it is referred to be a vehicle in the direction of that character in that novel.

The following phrasal verb is (Macmillan Dictionary, 2002) get along. So, if two or more people get along, it means, they like each other and are friendly to each other. Sentence: I don't really get along with my sister's husband. It is syntactically taken from the novel; "...we are going to get along and have fun." Explanation: Phrasal verb on that sentence is get along. It is called phrasal verb because there is a verb get followed by a particle along. The word get along on that sentence is included in intransitive phrasal verb because after the phrasal verb there is no direct object. It means as 'to make friends'. So, it is elaborated as those-being-pointedcharacters tend to like each other and are friendly to each other. In short of beside saying it is friendly, it is compatible or being melted as the friendship zone with each other.

The next phrasal verb (Macmillan Dictionary, 2002) is get down. It is interpreted as to lower the head and body quickly in order to avoid of being hit or touched by something. Example: Incoming fire! Get down! It is syntactically taken from the novel; "Now, who is going to get down?" Explanation: Phrasal verb on that sentence is get down. It is called phrasal verb because there is a verb get followed by a particle down. The word get down on that sentence is included in intransitive phrasal verb because after the phrasal verb there is no direct object. It is classified into inseparable phrasal verb because between the word get and particle down 
there is no object. It means 'to descend'. Within the novel, that person is trying to move down from a certain place. Also, it is also defined as to be going down.

The rid of in accordance with (Collins English Dictionary, 1979), can be stated by to not now have an unwanted or unpleasant task, object, or person. Simply statement says: I didn't enjoy marking those papers and I was glad to be rid of them. It is syntactically taken from the novel; "I'd like to get rid of the bear, but the campers love him." Explanation: Phrasal verb on that sentence is rid of. It is called phrasal verb because there is a verb rid and a particle of. It is classified into transitive inseparable phrasal verb because after the phrasal verb rid of, it is directly followed by direct object her bear. It means 'to throw something'. It is absolutely aimed to be to removing or throwing away something unwanted from that character (She is Sabrina) of that novel. On the other hand, it is interpreted as, to do something so as to no longer have or be affected or bothered by (someone that is unwanted).

The hold on as phrasal verb (Macmillan Dictionary, 2002) is grasp or support something with one's hands. Also, it is to wait; stop. Example: "Hold on! Slow down a bit!" It is syntactically taken from the novel; "Hold on!" barked Sabrina. "Who are you?" Explanation: Phrasal verb on that sentence is hold on. It is called phrasal verb because there is a verb hold followed by a particle on. The word hold on on that sentence is included in intransitive phrasal verb because after the phrasal verb there is no direct object. It means 'to wait'. Exactly, that person (Sabrina) wants to the interlocutor to be telling someone to wait for a short time. It is to await someone; it is to hold someone tightly or carefully.

Afterwards, jumped back as the kind of phrasal verb, (Macmillan Dictionary, 2002) which can be means as pushing somebody suddenly off the ground and into the air by using the legs. Example: Why don't you just jump back into the Earth fountain? It is syntactically taken from the novel; "She shrieked and jumped back." Explanation: The Phrasal verb on that sentence is jumped back. It is called phrasal verb because there is a verb jumped followed by a particle back. The word jumped back on that sentence is included in intransitive phrasal verb because there is no object after the phrasal verb. It is classified into inseparable phrasal verb because between a word jump and a particle back there is not an object. It means 'to hop to the back'. Then, it is to move backwards. The person shows, he is Jack Emmanuel, the activity of moving or jumping, but it is done backwardly.

The keep away is from (Macmillan Dictionary, 2002)'s reference. It is meant as maintain a physical separation, as between two or more people or things. Example tells: Kids, keep away from that beehive! It is syntactically taken from the novel; "Keep that kleptomaniac away from your stuff!" Explanation: Phrasal verb on that sentence is keep away from. It is called phrasal-prepositional verb because there is a verb keep, a particle away and prepositional verb from. It is classified into transitive-separable phrasal verb because there is an object between the verb keep and particle away. It means 'to make a distance from someone'. It needs a space or distance between the people (Tara and Sicca) in that novel being talked or discussed to. It is separated by a certain gap.

The following phrasal verb (Longman Dictionary of Contemporary English, 1978), it is kick out of, which means to feel amusement, delight or excitement about something or someone. Example: I really get a kick out of watching my two-year-old 
nephew-he's so naughty. It is syntactically taken from the novel; "...., and she got kicked out of another cabin." Explanation: Phrasal verb on that sentence is kicked out of. It is called phrasal verb because there is a verb kicked, a particle out, and prepositional verb of. It is classified into transitive inseparable phrasal verb because after the phrasal verb kicked out of, it is directly followed by direct object another cabin. It means 'to repel'. It is to dismiss or eject forcefully or summarily. In that novel, the girl is force to leave or being moved out. She is trying to hit Jason Pedro with legs, because that person is looking angry or upset of such an internal problem or conflict there.

As for the look after (Longman Dictionary of Contemporary English, 1978) as he phrasal verb, it means to take care of someone or something and make certain that they have everything they need. Example: Still, it felt secure to have someone look after her the way he did. It is syntactically taken from the novel; "I'll have to look after you ...." Explanation: Phrasal verb on that sentence is look after. It is called phrasal verb because there is a verb look and a particle after. It is classified into transitive inseparable phrasal verb because after the phrasal verb look after, it is directly followed by direct object you. It means 'to take care'. That person takes care of someone or something, in this case, the person being talked is Alex Ferguson. So, that person takes care toward him and make certain that she has everything he needs.

The send back to (Longman Dictionary of Contemporary English, 1978) will be meant to return something to the person who sent it to somebody. Example: I had to send the shirt back because it didn't fit me. It is syntactically taken from the novel; "Before Sabrina could send the cat back to his litter box." Explanation: Phrasal verb on that sentence is send back to. It is called phrasal-prepositional verb because there is a verb send, a particle back and prepositional verb to. It is classified into transitive-separable phrasal verb because there is an object between the verb send and particle back. It means, 'to return'. Sabrina returns something to the place it came from. In addition, she gives back (it is a feline) to its origin; that is her brother, Jack Emmanuel.

Table 1. The Result of Phrasal Verbs Found

\begin{tabular}{lll}
\hline No. & \multicolumn{1}{c}{ Kinds of Phrasal Verbs } & \multicolumn{1}{c}{ Total } \\
\hline 1. & Intransitive phrasal verbs & Five \\
2. & Transitive separable phrasal verbs & Sixteen \\
3. & Transitive inseparable phrasal verbs & Eleven \\
4. & Separable phrasal verbs & Four \\
\hline
\end{tabular}




\section{CONCLUSION}

In common, English has a number of verbs used with particles; the examples are: get up, take off, sit down, go out and many more. The verbs include get, go, come, take, make, do, and the particles include words such as up, in, out, on, off, down. They are called as phrasal verb. These phrasal verbs are common quite in everyday usage.

However, within Eat, Pray, Love novel written by Elizabeth Gilbert, it has several frequently used verbs and particles in English. So, as being scrutinized keenly, it can be concluded or being drawn for the conclusion that, after classifying or categorizing into four sub-discussions, they are either; Transitive, Intransitive, Separable, or Inseparable there, it turns out within this novel which shows: 20 phrasal verbs found here. Deeply statement of getting to be breaking down, the result or outcome states that, there are five intransitive phrasal verbs, sixteen transitive separable phrasal verbs, eleven transitive inseparable phrasal verbs, and the last, four separable phrasal verbs.

Based on the classification then, it is revealed that phrasal verb has an exact definition. Certainly, it needs a current context first (read and understand in a certain dialogue or conversation inside that novel of Eat, Pray, Love) to know what the meaning of that case or topic being conveyed is. Afterwards, the real meaning of the phrasal verb in the novel will be clearly understood.

\section{REFERENCES}

Andria, R. (2021). Transitive and Intransitive Phrasal Verbs List. EnglishBix.

Anggraeni, D. (2020). A Separable and Inseparable Transitive Phrasal Verbs. International Journal of Social, Politics, and Humanities, 3, 42.

Aryani, P. (2019). An Analysis of Phrasal Verb Found in Premise Journal of English Education Study Program of Muhammadiyah. Journal of English Education and Entrepreneurship, 1.

Collins English Dictionary. (1979). Harper Collins.

Dictionary, U. (1999). Aaron Pechkam.

Fiktorius, T. (2019). The Relationship between Transitive and Intransitive Verbs in English Language. Journal of Linguistics, Literature, and Culture, 01.

Greenbaum, Sidney and Nelson, G. (2002). An Introduction to English Grammar (2nd ed.). Pearson Education Limited.

Hornby. (2018). Language Style Used in J.K. Rowling's Harry Potter and The Cursed Child. English and Literature Journal, 5.

Kamus Inggris. (2000). John M. Echols \& Hassan Shadily.

Lock, G. (1996). Functional English Grammar: An Introduction for Second Language Teachers. Cambridge University Press.

Longman Dictionary of Contemporary English. (1978). Paul Procter.

Macmillan Dictionary. (2002). Rundell, Michael.

Monika, D. M. (2020). An Analysis of Phrasal Verb Errors Used by Fifth Semester Students of English Study Program of IAIN, Bengkulu. IAIN Bengkulu.

Mutiara, Sofwan, \& K. (2017). An Analysis of English Phrasal Verb Translation in Totto Chan Novel: The Little Girl at The Window. Journal of English Language Teaching, 6.

Nordquist, R. (2013). Branches of Linguistics. Humanities. https://www.thoughtco.com/what-is-linguistics-1691012 
41 J-Lalite: Journal of English Studies Vol.2, No.1, June, 2021

Rahmawati, J. (2013). Phrasal Verbs in Novel Sabrina The Teenage Witch: Prisoner of Cabin 13 Written by John Vornholt.

Tu, T. P. N. \& T. Q. T. (2019). The Use of Phrasal Verbs in English Language Research Proposals by Vietnamese M.A. Student. Journal of Foreign Studies.

Webster, N. (2021). Merriam Webster.

Wikasitakusumaning, A. (2018). Analysis Kinds of Phrasal Verbs in The Ted Talk Speech "The Power Of Introverts" Produced By Susan Cain in Edition on March 2018. IAIN Salatiga, West Java.

Yuliastuti, W. (2008). A Study of the Particles of Phrasal, Prepositional, and PhrasalPrepositional Verbs in Oxford Advanced Learner's Dictionary of Current English. 